\title{
Individual patient-data meta-analysis comparing clinical outcome in patients with ST-elevation myocardial infarction treated with percutaneous coronary intervention with or without prior thrombectomy. ATTEMPT study: A pooled Analysis of Trials on ThrombEctomy in acute Myocardial infarction based on individual PatienT data
}

\author{
Maria De Vita' \\ Francesco Burzotta' \\ Giuseppe GL Biondi-Zoccai² \\ Thierry Lefevre ${ }^{3}$ \\ Dariusz Dudek ${ }^{4}$ \\ David Antoniucci ${ }^{5}$ \\ Pedro Silva Orrego ${ }^{6}$ \\ Leonardo De Luca $^{7}$ \\ Anne Kaltoft ${ }^{8}$ \\ Gennaro Sardella ${ }^{9}$ \\ Felix Zijlstra ${ }^{10}$ \\ Takaaki Isshikil" \\ Filippo Crea' \\ 'Cardiology Institute, Catholic \\ University of Sacred Heart, Rome, \\ Italy; ${ }^{2}$ Interventional Cardiology, \\ University of Turin, Italy; ${ }^{3}$ ICPS, Massy, \\ France; ${ }^{4}$ Department of Cardiology, \\ Jagiellonian University, Kracow, \\ Poland; ${ }^{5}$ Division of Cardiology, \\ Careggi Hospital, Florence, Italy; \\ 'Interventional Cardiology, A De \\ Gasperis Department, Niguarda \\ Hospital, Milan, Italy; ${ }^{7}$ Department \\ of Cardiovascular Sciences, \\ European Hospital, Rome, Italy; \\ ${ }^{8}$ Department of Cardiology, Aarhus \\ University Hospital, Skejby, Denmark; \\ ${ }^{9}$ Department of Cardiovascular and \\ Respiratory Sciences, La Sapienza \\ University, Rome, Italy; ${ }^{10}$ University \\ Medical Center Groningen, Groningen, \\ the Netherlands; "Department of \\ Cardiology, Teykio University School \\ of Medicine, Tokyo, Japan
}

Correspondence: Maria De Vita

Catholic University of Sacred Heart,

Cardiology Institute, Largo F Vito,

I, 00168 Rome, Italy

Tel +390630154187

Fax +3906 3055535

Email mariarosariadevita77@libero.it
Background: Available data from randomized trials on thrombectomy in patients with ST-elevation myocardial infarction (STEMI) have shown favorable trends in myocardial reperfusion. However, few data are available on the effect of thrombectomy on clinical outcome. Thus we have designed a collaborative individual patient-data meta-analysis which aimed to assess the long-term clinical outcome in STEMI patients randomized to percutaneous coronary intervention (PCI) with or without thrombectomy.

Method: After a thorough database search, the principal investigators of randomized trials comparing thrombectomy with standard PCI in patients with STEMI were contacted. Principal investigators as authors of 11 randomized studies agreed to participate and were asked to complete a structured database by providing a series of key pre-PCI clinical and angiographic data as well as the longest available clinical outcome of the patients enrolled in the corresponding trial. The primary end-point of this pooled analysis is the comparison of overall survival rates between patients randomized to PCI with thrombectomy or PCI without thrombectomy. The secondary end-points are survival free from myocardial infarction (MI), target lesion revascularization (TLR), major adverse coronary events (MACE: death + MI + TLR) and death + MI between patients randomized to PCI with thrombectomy or PCI without thrombectomy. A pre-defined subgroup analysis is planned considering the following variables: type of thrombectomy device used, diabetes, rescue PCI, IIb/IIIa-inhibitors use, time-to-reperfusion, infarct-related artery, and pre-PCI TIMI flow.

Implications: This study will provide useful data on the effect of the reported improved myocardial perfusion associated with thrombectomy on the long-term clinical outcome in patients with STEMI.

Keywords: ST elevation myocardial infarction, thrombectomy, primary PCI

\section{Introduction}

Primary percutaneous coronary intervention (PCI) has been shown to provide mortality benefits in comparison with thrombolysis, mainly because of better and sustained optimal coronary perfusion. ${ }^{1}$ However, despite epicardial recanalization with Thrombolysis in Myocardial Infarction Trial 3 (TIMI 3) flow, myocardial reperfusion is not achieved in up to $40 \%$ of patients, with a significant effect on their long-term survival. ${ }^{2,3}$ Atherothrombotic embolization is considered to play an important role in the pathogenesis of this "no-reflow phenomenon." Accordingly, a series of adjunctive devices with different 
antiembolic properties (thrombectomy or distal protection) has been developed and tested in clinical studies with conflicting results. Nevertheless, a meta-analysis of prospective randomized trials ${ }^{5}$ suggests that the use of thrombectomy devices, but not distal protection devices, may be associated with a significant reduction of angiographically evident distal embolization and with higher rates of myocardial blush grade (MBG) 3 and ST-segment resolution.

Because angiographic and electrocardiographic markers of myocardial reperfusion are well known predictors of late clinical outcome, ${ }^{3,6-9}$ the use of thrombectomy may also translate to a clinical advantage. Unfortunately, most of the trials on thrombectomy have been based on a small sample size and short follow-up for reliable assessment of clinical benefit. Only one, recently published, single-center trial conducted on 1071 patients with ST-elevation myocardial infarction (STEMI), showed an advantage of thrombus-aspiration use in terms of mortality at one year follow-up. ${ }^{10}$

To extend the investigation on this issue to a larger population, we have designed a pooled analysis of the individual patient data of prospective randomized trials comparing standard PCI with or without thrombectomy, to evaluate the influence of thrombectomy use on clinical outcome.

\section{Design and method Study design}

Individual patient data meta-analysis. The study protocol was initiated in October 2007 (by FB, MDV, and FC) and the first final manuscript design drafting was completed on January 10th, 2008.

\section{Method}

A systematic MEDLINE database search (see http://www. ncbi.nlm.nih.gov/) for studies comparing standard PCI with thrombectomy (T) with standard PCI only (SP) was conducted according to a modified Robinson and Dickersin strategy. ${ }^{11}$ Keywords were "STEMI," "randomized," "thrombus aspiration," and "thrombectomy." The TCTMD (see http://www.tctmd.com/), EuroPCR (see http://www. europcr.com/), American College of Cardiology (see http://www.acc.org/), America Heart (see http://www. americaheart.org/), and European Society of Cardiology (see http://www.escardio.org/) websites were searched for pertinent abstracts and expert slide presentations between October 2003 and February 2008. No language restriction was applied.

Inclusion criteria for selected studies were: 1. comparison of $\mathrm{T}$ with SP in patients with STEMI; 2. randomized treatment allocation. The exclusion criterion was the equivocal treatment allocation process.

Thirteen studies published as full papers ${ }^{12-24}$ and four additional studies ${ }^{25-28}$ published as abstracts and/or slide presentations (Noel B, ${ }^{28}$ from the EuroPCR 2005 meeting; the PIHRATE trial; ${ }^{25}$ the expert slide presentation from the TCTMD 2007 meeting; the EXPIRA trial; ${ }^{26}$ expert slide presentations on the Transcatheter Cardiovascular Therapeutics website (see http://www.tct2007.com/); and the Export study ${ }^{27}$ expert slide presentations on the Transcatheter Cardiovascular Therapeutics website were identified.

The 15 principal investigators of these 17 identified studies were contacted by mail or fax to participate in the ATTEMPT study (meta-Analysis of Trials on ThrombEctomy in acute Myocardial infarction based on individual PatienT data), a meta-analysis based on individual patient data to compare the long-term clinical outcome between thrombectomy and standard PCI in patients with STEMI enrolled in the selected randomized trials.

All 10 principal investigators who agreed to participate were asked to complete a structured database including standard baseline clinical and angiographic data as well as the longest available clinical outcome data of each patient previously enrolled in the corresponding trial.

This individual patient data will be sent to the study coordinator (MDV) who will be responsible for the final pooling in a single database.

A statistical expert (GBZ) will be responsible for statistical analyses. All the principal investigators will be informed about the status of the project by regular newsletters.

\section{End points}

The primary end-point of the study will be to compare rates of overall survival in patients randomized to T or SP. Secondary end-points will be survival free from myocardial infarction (MI), target lesion revascularization (TLR), major adverse coronary events (MACE: death + MI + TLR) and death + $\mathrm{MI}$ between patients randomized to $\mathrm{T}$ or SP.

\section{Pre-defined subgroup analyses}

The comparison of clinical outcome between patients randomized to T and SP will be performed according to:

1. Type of thrombectomy device (manual thrombus aspiration devices versus non-manual thrombectomy devices)

2. Presence or absence of diabetes mellitus

3. Rescue PCI or primary PCI 
4. Administration or no administration of IIb/IIIa-inhibitors

5. Time-to-reperfusion $(\leq 3 \mathrm{~h}$ or between $3 \mathrm{~h}$ and $6 \mathrm{~h}$ or $>6 \mathrm{~h}$ )

6. Infarct-related artery (LAD or LCX or RCA)

7. Pre-PCI TIMI flow (TIMI 0-1 or TIMI 2-3)

\section{Sample size calculation and study feasibility}

A meta-analysis of randomized trials comparing thrombectomy with standard PCI in patients with STEMI ${ }^{5}$ showed a rate of myocardial blush grade 3 (MBG 3) significantly higher in the thrombectomy group: odds ratio [OR] 2.32 (1.28-4.21). Moreover, van't Hof and colleagues demonstrated that the post-PCI MBG is a strong predictor of long-term mortality in patients with STEMI treated with primary PCI. In particular they reported, after a mean follow-up of $1.9 \pm 1.7$ years, a total mortality rate of $3 \%$ in patients with post-PCI MBG 3 and of $29 \%$ in patients with post-PCI $\mathrm{MBG}<3 .{ }^{3}$ Given these results, we anticipated a sample size of 1350 patients to demonstrate an advantage in terms of mortality at one year using thrombectomy, with an alpha risk of $5 \%$ and a beta risk of $20 \%$.

\section{Study population}

To date, 10 principal investigators of 11 randomized studies agreed to participate in the ATTEMPT study and provided the requested data. The key characteristics of these 11 randomized studies are summarized in Table 1.
The ATTEMPT study population will comprise all the patients enrolled in the randomized studies entered in this single patient data meta-analysis. The key characteristics of the study populations recruited in the 11 studies are summarized in Table 2.

\section{Statistical analysis}

Continuous variables will be reported as mean \pm standard deviation or median (1st-3rd quartiles), and categorical variables as n (\%), unless otherwise stated. Statistical pooling will be based on the Peto fixed effect method for patient-level analysis (according to event counts reported at the longest available follow-up), and a random effect method with generic inverse variance weighting (according to risk estimates obtained with Cox proportional hazard analysis). In this way we can compute pooled OR and hazard ratios (HR) with their corresponding 95\% confidence intervals. Kaplan-Meier curves will be computed for survival and event-free survival analyses, both crude and stratified by study, with statistical testing based on log-rank test. Multivariable analyses, logistic or proportional hazard as appropriate will also be conducted by clustering patients according to each study. A two-tailed $p$ value of 0.05 was chosen as the cut-off for statistical significance at hypothesis testing, whereas we plan to appraise statistical inconsistency by means of $\mathrm{I}^{2}$, with values $>50 \%$ identifying subsets with at least moderate heterogeneity. Finally, publication bias will be appraised by means of funnel plot inspection and Egger test.

Table I Key characteristics of the trials entered in the ATTEMPT study

\begin{tabular}{|c|c|c|c|c|c|c|}
\hline Study & Design & $\begin{array}{l}\text { Thrombectomy } \\
\text { device }\end{array}$ & $\begin{array}{l}\text { Num } \\
\text { SP T }\end{array}$ & patients & $\begin{array}{l}\text { Pre-coronary time } \\
\text { limit (hours) }\end{array}$ & $\begin{array}{l}\text { Longest published } \\
\text { clinical FU }\end{array}$ \\
\hline VAMPIRE $^{19}$ & Multicenter & TVAC & 175 & 180 & $<24$ & In hospital \\
\hline X-AMINE ST ${ }^{17}$ & Multicenter & X-Sizer & 101 & 100 & $<12$ & Six months \\
\hline DEAR-MI (19) & Single center & Pronto & 74 & 74 & $<12$ & In hospital \\
\hline Antoniucci et al ${ }^{14}$ & Single center & Angiojet & 50 & 50 & $<6$ & 30 days \\
\hline REMEDIA $^{16}$ & Single center & Diver CE & 50 & 49 & $<12$ & In hospital \\
\hline Noel et a ${ }^{28}$ & Single center & Export & 26 & 24 & $<12$ & In hospital \\
\hline Kaltoft et al ${ }^{20}$ & Single center & Rescue & 107 & 108 & $<12$ & 30 days \\
\hline De Luca et $\mathrm{al}^{21}$ & Single center & Diver CE & 38 & 38 & $<12$ & Six months \\
\hline PIHRATE $^{25}$ & Multicenter & Diver CE & 94 & 102 & $<6$ & Six months \\
\hline EXPIRA $^{26}$ & Single center & Export & 87 & 88 & $<12$ & Nine months \\
\hline TAPAS trial ${ }^{24}$ & Single center & Export & 536 & 535 & $<12$ & One year \\
\hline $\begin{array}{l}\text { ATTEMPT study } \\
\text { population }\end{array}$ & - & - & 1338 & 1348 & - & - \\
\hline
\end{tabular}

Abbreviations: FU, follow-up; NA, not available; $\mathrm{PCl}$ percutaneous coronary intervention; SP, standard PCl; T, thrombectomy device treatment. 
Table 2 Key characteristics of the study population in the II trials entered in the ATTEMPT study

\begin{tabular}{|c|c|c|c|c|c|c|c|}
\hline Study & $\begin{array}{l}\text { Age } \\
\text { (mean) }\end{array}$ & $\begin{array}{l}\text { Diabetes } \\
(\%)\end{array}$ & $\begin{array}{l}\text { Ilb/llla } \\
\text { inhibitors } \\
(\%)\end{array}$ & $\begin{array}{l}\text { Failed } \\
\text { TL (\%) }\end{array}$ & $\begin{array}{l}\text { Anterior } \\
\text { MI ๆ(\%) }\end{array}$ & $\begin{array}{l}\text { Mean } \\
\text { symptom-to } \\
\text { balloon time } \\
\text { (minutes) }\end{array}$ & $\begin{array}{l}\text { Baseline TIMI } \\
\text { flow 0-I (\%) }\end{array}$ \\
\hline VAMPIRE $^{19}$ & 63 & 26 & 0 & 0 & 51 & $291 *$ & 75 \\
\hline X-AMINE ST ${ }^{17}$ & 61 & 22 & 51 & 0 & 52 & 257 & 100 \\
\hline DEAR-MI'18 & 59 & 18 & 100 & 0 & 47 & 130 & 78 \\
\hline Antoniucci et al ${ }^{14}$ & 65 & 17 & 98 & 0 & 40 & 249 & 78 \\
\hline REMEDIA $^{16}$ & 60 & 21 & 69 & 38 & 45 & $280^{\S}$ & 88 \\
\hline Noel et a ${ }^{28}$ & 60 & 13 & NA & 34 & 44 & 282 & NA \\
\hline Kaltoft et $\mathrm{al}^{20}$ & 64 & 7 & 95 & 0 & 44 & 225 & 69 \\
\hline De Luca et $\mathrm{al}^{21}$ & 65 & 21 & 100 & 0 & 100 & 438 & 100 \\
\hline PIHRATE 25 & 60 & 10 & 62 & 0 & NA & 200 & 100 \\
\hline EXPIRA $^{26}$ & 66 & 17 & 75 & 0 & 100 & 390 & 100 \\
\hline TAPAS study ${ }^{24}$ & 63 & 12 & 92 & 0 & 43 & 187 & 57 \\
\hline
\end{tabular}

Abbreviations: MI, myocardial infarction;TS, thrombolysis; $\uparrow$, in the studies with missing anterior MI rate patients with left anterior descending artery as culprit artery where considered to have anterior MI; §, symptom to angiography time; *, symptom to hospital admission time; NA, not available.

\section{Discussion}

The clinical data from a meta-analysis of 18 trials on adjunctive devices in patients with STEMI show that use of thrombectomy devices is associated with better myocardial reperfusion, which does not translate, however, to a lower rate of mortality or MI at 30 days. ${ }^{5}$ This short follow-up time might be insufficient to show a clinical benefit. Of note, two recent nonrandomized studies comparing Angio-jet with SP in STEMI patients with a high thrombus burden reported a significant reduction of long-term mortality. ${ }^{29,30}$ Moreover, very recent data from the randomized EXPIRA trial (Sardella, personal communication at TCT 2007 meeting) and the randomized TAPAS trial showed respectively a strong trend toward lower mortality at nine months ${ }^{26}$ and a significantly lower mortality at 12 months in the group of patients treated with thrombectomy.$^{10}$ Therefore the available data support the possible advantage of thrombectomy on long-term clinical outcome. Because angiographic analyses have shown that thrombectomy may have different efficacy in different patients, ${ }^{31}$ the clinical benefit of thrombectomy use may be more pronounced in some subgroups of patients. Thus previous studies showed a greater advantage using thrombectomy for reperfusion in patients with baseline TIMI flow $0-1$, baseline thrombus score 3-4 or angiographically evident thrombus-containing lesions. ${ }^{16,22}$ For these reasons, the design of the present study planned for subgroup analyses of patients stratified according to a series of key clinical, angiographic, and procedural variables.

In conclusion the aim of the ATTEMPT study is to assess if thrombectomy, by improving myocardial reperfusion, can influence the long-term clinical outcome in particular in some high risk subgroups of STEMI patients such as those with a higher thrombus burden or a large amount of myocardium at risk.

\section{Expected study limitations}

As a consequence of the ATTEMPT study design, the quality of the results will be influenced by the quality of the design of each original trial. In particular, no quality control has been planned so that each participant principal investigator will be completely responsible for the quality control of the data entered in the ATTEMPT database. No restriction in trial size, publication status (full paper or abstract presentation) and length of updated clinical follow-up has been applied. Consequently, some of the trials included are single-center and/or small-sized, and the length of patient follow-up will be not uniform.

All these anticipated limitations have been accepted in an effort to achieve the goal of wide participation in the study. Such extensive collaboration was sought to better summarize the available data obtained to date by the scientific community. Thus publication bias assessment has been planned according to validated statistical techniques.

Another possible limitation may arise from the fact that different definitions may have been adopted across the trials included in the analysis. In particular, the definition of device failure differed across the studies so that a reliable pooled estimate of device efficacy will not be possible. Nevertheless, the planned primary "intention-to-treat" analysis selected for the 
present study is not expected to be influenced by such factors. Moreover, the presence of (minor) heterogeneity among some clinical end-point (like myocardial infarction, target vessel, or target lesion revascularization) definitions adopted across the trials will not influence the primary end-point analysis which is focused on the univocal all-cause mortality.

\section{Disclosure}

The authors declare no conflicts or competing interests in this work.

\section{References}

1. Keeley EC, Boura JA, Grines CL. Primary angioplasty versus intravenous thrombolytic therapy for acute myocardial infarction: a quantitative review of 23 randomised trials. Lancet. 2003;361:13-20.

2. Rezkalla SH, Kloner RA. No-reflow phenomenon. Circulation. 2002;105:656-662.

3. van 't Hof AW, Liem A, Suryapranata H, Hoorntje JC, de Boer MJ, Zijlstra F. Angiographic assessment of myocardial reperfusion in patients treated with primary angioplasty for acute myocardial infarction: myocardial blush grade. Zwolle Myocardial Infarction Study Group. Circulation. 1998;97:2302-2306.

4. Erbel R, Heusch G. Coronary microembolization. J Am Coll Cardiol. 2000;36:22-24.

5. Burzotta F, Testa L, Giannico F, et al. Adjunctive devices in primary or rescue PCI: a meta-analysis of randomized trials. Int J Cardiol. 2008;123:313-321.

6. Henriques JP, Zijlstra F, Ottervanger JP, et al. Incidence and clinical significance of distal embolization during primary angioplasty for acute myocardial infarction. Eur Heart J. 2002;23:1112-1117.

7. Gibson CM, Cannon CP, Murphy SA, et al. Relationship of TIMI myocardial perfusion grade to mortality after administration of thrombolytic drugs. Circulation. 2000;101:125-130.

8. Schröder K, Wegscheider K, Zeymer U, Tebbe U, Schroder R. Extent of ST-segment deviation in a single electrocardiogram lead $90 \mathrm{~min}$ after thrombolysis as a predictor of medium-term mortality in acute myocardial infarction. Lancet. 2001;358:1479-1486.

9. Reffelmann T, Kloner RA. The "no-reflow" phenomenon: basic science and clinical correlates. Heart. 2002;87:162-168.

10. Vlaar PJ, Svilaas T, van der Horst IC, et al. Cardiac death and reinfarction after 1 year in the Thrombus Aspiration during Percutaneous coronary intervention in Acute myocardial infarction Study (TAPAS): a 1-year follow-up study. Lancet. 2008;371:1915-1920.

11. Biondi Zoccai GG, Agostoni P, Abbate A, Testa L, Burzotta F. A simple hint to improve Robinson and Dickersin's highly sensitive PubMed search strategy for controlled clinical trials. Int J Epidemiol. 2005;34:224-225.

12. Beran G, Lang I, Schreiber W, Denk S. Intracoronary thrombectomy with the X-Sizer catheter system impreves epicardial flow and accelerates ST-segment resolution in patients with acute coronary syndrome. Circulation. 2002;105:2355-2360.

13. Napodano M, Pasquetto G, Sacca S, et al. Intracoronary thrombectomy improves myocardial reperfusion in patients undergoing direct angioplasty for acute myocardial infarction. $\mathrm{J} \mathrm{Am} \mathrm{Coll} \mathrm{Cardiol.}$ 2003;42:1395-1402.

14. Antoniucci D, Valenti R, Migliorini A, et al. Comparison of rheolitic thrombectomy before direct infarct artery stenting versus direct stenting alone in patients undergoing percutaneous coronary intervention of acute myocardial infarction. Am J Cardiol. 2004;93:1033-1035.

15. Dudek D, Mielecki W, Legutko J, et al. Percutaneous thrombectomy with the RESCUE system in acute myocardial infartion. Kardiol Pol. 2004;61:523-533.
16. Burzotta F, Trani C, Romagnoli E, et al. Manual thrombus-aspiration improves myocardial reperfusion: the randomized evaluation of the effect of mechanical reduction of distal embolization by thrombusaspiration in primary and rescue angioplasty (REMEDIA) trial. $\mathrm{J} \mathrm{Am}$ Coll Cardiol. 2005;46:371-376.

17. Lefevre T, Garcia E, Reimers B, et al; X AMINE ST Investigators. $\mathrm{X}$-sizer for thrombectomy in acute myocardial infarction improves ST-segment resolution: results of the X-sizer in AMI for negligible embolization and optimal ST resolution (X AMINE ST) trial. J Am Coll Cardiol. 2005;46:246-252.

18. Silva-Orrego P, Colombo P, Bigi R, et al. Thrombus aspiration before primary angioplasty improves myocardial reperfusion in acute myocardial infarction: the DEAR-MI (Dethrombosis to Enhance Acute Reperfusion in Myocardial Infarction) study. J Am Coll Cardiol. 2006;48:1552-1559.

19. Ikari Y, Sakurada M, Kozuma K, et al; VAMPIRE Investigators. Upfront thrombus aspiration in primary coronary intervention for patients with ST-segment elevation acute myocardial infarction. Report of the VAMPIRE (VAcuuM asPIration thrombus REmoval) Trial. J Am Coll Cardiol Intv. 2008;1:424-431.

20. Kaltoft A, Bottcher M, Nielsen SS, et al. Routine thrombectomy in percutaneous coronary intervention for acute ST-segment-elevation myocardial infarction: a randomized, controlled trial. Circulation. 2006;114:40-47.

21. De Luca L, Sardella G, Davidson CJ, et al. Impact of intracoronary aspiration thrombectomy during primary angioplasty on left ventricular remodelling in patients with anterior ST elevation myocardial infarction. Heart. 2006;92:951-957.

22. Ali A, Cox D, Dib N, et al; AIMI Investigators. Rheolytic thrombectomy with percutaneous coronary intervention for infarct size reduction in acute myocardial infarction: 30-day results from a multicenter randomized study. J Am Coll Cardiol. 2006;48:244-252.

23. Ozaki Y, Nomura M, Nakayama T, et al. Effects of thrombus suction therapy on myocardial blood flow disorders in males with acute inferior myocardial infarction. J Med Invest. 2006;53:167-173.

24. Svilaas T, Vlaar PJ, van der Horst IC, et al. Thrombus aspiration during primary percutaneous coronary intervention. $N \mathrm{Engl} \mathrm{J} \mathrm{Med.}$ 2008;358:557-567.

25. Dudek D. Polish-Italian-Hungarian Randomized ThrombEctomy Trial. PHIRATE trial; Expert slide presentation from Late Breaking Clinical Trials, TCT 2007. Cited on February 10, 2009. Available from: http:// www.tctmd.com.

26. Sardella G, Mancone M, Bucciarelli-Ducci C, et al. Thrombus aspiration during primary percutaneous coronary intervention improves myocardial reperfusion and reduces infarct size: the EXPIRA (thrombectomy with export catheter in infarct-related artery during primary percutaneous coronary intervention) prospective, randomized trial. J Am Coll Cardiol. 2009;53(4):309-315.

27. Chevalier B. Export Study; Expert slide presentation from Late Breaking Clinical Trials, TCT 2007. Cited on February 10, 2009. Available from: http://www.tctmd.com.

28. Noel B, Morice MC, Lefevre T, et al. Thrombus aspiration in acute ST-elevation myocardial infarction: a randomized controlled trial Circulation. 2005;112(Suppl II):519.

29. De Rosa S, Cirillo P, De Luca G, et al. Rheolytic thrombectomy during percutaneous coronary intervention improves long-term outcome in high-risk patients with acute myocardial infarction. J Interv Cardiol. 2007;20:292-298.

30. Sianos G, Papafaklis M, Daemen J, et al. Rheoliytic thrombectomy in patients with ST-elevation myocardial infarction and large thrombus burden: the Thoraxcenter Experience. J Invasive Cardiol. 2006;18:1042-1049.

31. Burzotta F, Trani C, Romagnoli E, et al. A pilot study with a new, rapid-exchange, thrombus-aspirating device in patients with thrombuscontaining lesions: the Diver C.E. study. Catheter Cardiovasc Interv. 2006;67:887-893 
